6. Skulachev VP. Why are mitochondria involved in apoptosis? Permeability transition pores and apoptosis as selective mechanisms to eliminate superoxide-producing mitochondria and cell. FEBS Lett 1996;397:7-10.

7. Chalmers RM, Harding AE. A case-control study of Leber's hereditary optic neuropathy. Brain 1996;119:1481-6.

Brian Redmill

Anthony Mutamba

Mike Tandon

Department of Ophthalmology

Frimley Park Hospital

Camberley, UK

Mr B. Redmill

Lincoln County Hospital

Greetwell Road

Lincoln LN2 5QY, UK

Tel: +44 (0)1522 573949

e-mail: brian.redmill@mac.com

Sir,

\section{Episcleral osseous choristoma}

Episcleral osseous choristoma is a rare benign lesion of episcleral connective tissue that characteristically occurs in otherwise normal eyes. It was first described by Von Graefe in 1863.

\section{Case report}

An 8-year-old Caucasian girl presented with a 6 month history of a slowly enlarging painless lump on the upper outer corner of her left eye. Examination revealed a peasized, whitish, firm subconjunctival lesion in the superior temporal quadrant of the left eye (Fig. 1). The remainder of the ocular examination showed no abnormalities. A diagnosis of epibulbar dermoid was made. The tissue was excised under general anaesthesia.

Intraoperatively, adequate exposure of the lesion was obtained by inserting a 7/0 corneal fixation Ethilon suture at the limbus, adjacent to the lesion, and clipping the ends of the suture, on to the drapes, in the direction of the opposite quadrant. An incision was made into the conjunctiva overlying the lesion. The conjunctiva was

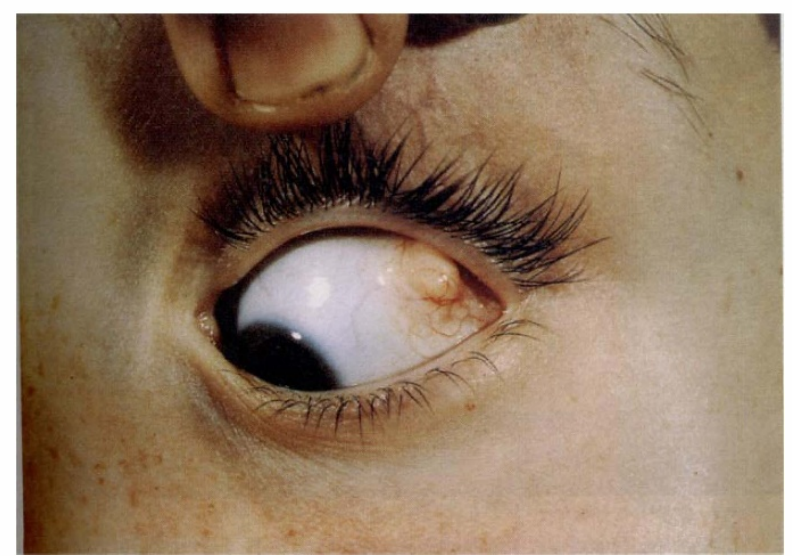

Fig. 1. Slit-lamp photograph of the subconjunctival lesion in the supero-temporal quadrant of the left eye.

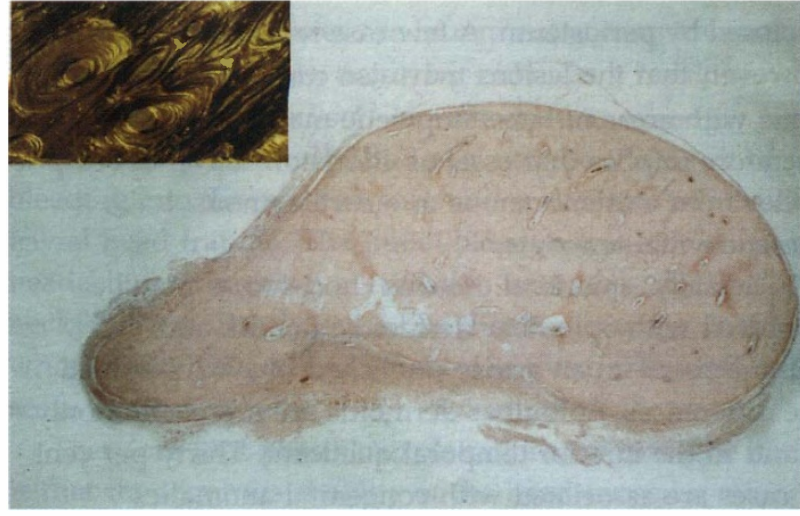

Fig. 2. Histological appearance of the excised lesion, showing dense compact lamellar bone, arranged in Haversian systems and enclosed by periosteum. This picture is characteristic of most episcleral osseous choristomas (HEE; $\times 4.5$ original magnification). Inset: Polarised filters $(\times 25$ original magnification)

dissected off the lesion using a pair of Wescott's scissors. Once adequate exposure was obtained, the lesion was carefully excised using a No. 15 Bard-Parker blade. Haemostasis was achieved with the aid of bipolar diathermy. The conjunctiva was repaired with interrupted $7 / 0$ vicryl sutures. The corneal fixation suture was removed and chloramphenicol ointment was applied topically. Thereafter, a protective Cartella shield was placed over the eye.

The specimen, a bony-hard ovoid nodule measuring $0.7 \mathrm{~cm}$, was placed in formalin solution and sent to the pathology department for histological assessment. This showed an osteoma composed of compact lamellar bone, namely a choristoma (Fig. 2).

\section{Comment}

Choristomas are defined as congenital overgrowth of normal tissue elements at sites where they do not normally occur. Single tissue choristomas consist of dermis-like tissue or ectopic tissue of meso-ectodermal origin, e.g. lacrimal and other glands, fat, brain, cartilage, bone and teeth. Complex or composite choristomas contain a combination of tissue from various origins. Osseous choristomas are rare lesions of the conjunctiva, episclera and choroid.

Episcleral osseous choristomas are usually detected in early infancy or childhood. They vary in size from pea- to almond-sized. They tend to increase in size either in early childhood or around puberty. ${ }^{2}$ Extraocular lesions commonly occur superotemporally, 5-10 $\mathrm{mm}$ from the limbus. There have, however, been a few case reports of occurrences at unusual locations. Oritz and Yannoff ${ }^{3}$ reported a case of epipalpebral osseous choristomas found in the conjunctiva of the right lower lid. Melki et $a l .{ }^{4}$ reported on a case involving the superior rectus sheath while Ferry and Hein ${ }^{5}$ reported on a lesion attached to the lateral rectus sheath. Macroscopically these lesions are composed of compact bone surrounded by fibrous tissue. The histological appearance is that of dense osseous tissue arranged in Haversian systems, and 
enclosed by periosteum. A few case reports have shown, however, that the lesions may also contain cancellous bone with areas of haematopoietic marrow. This therefore implies that osseous choristomas can develop either from a membranous or a cartilaginous mesenchymal template. ${ }^{6}$

Clinically, episcleral osseous choristomas may be confused with epibulbar dermoids. Bonuik and Zimmerman, ${ }^{7}$ in an article published in 1962, outlined the differences. Epibulbar dermoids are more commonly found in the inferior temporal quadrant. Thirty per cent of cases are associated with congenital anomalies involving malformations of the branchial arch derivatives, e.g. Goldenhar's syndrome. Histologically they consist of collagenous connective tissue covered by epithelium. It is important to remember, however, that epibulbar dermoids rarely contain bone tissue in addition to the dermis-like tissue and may hence pose a diagnostic radiological dilemma on skull radiographs or CT scans.

The aetiology and pathogenesis of these rare lesions remain obscure. They have no effect on vision and are not associated with any syndromes. Management is initially conservative. Surgery is indicated if the lesion becomes cosmetically unacceptable or symptomatic. The tumour is loosely attached and therefore easily shelled off the surface of the sclera.

To our knowledge, there have been no reports of recurrences or malignant transformation of episcleral osseous in the literature.

\section{References}

1. Von Graefe A. Tumour in submucosen Gewebe der Lidbindehaut von eigenthumlicher Beschafffenheit. Klin Monatsbl Augenheilkd 1863;1:23.

2. Mansour AM, et al. Ocular choristomas. Surv Ophthalmol 1989;33:??-??.

3. Oritz JM, Yannoff M. Epipalpebral conjunctival osseous choristomas. Br J Ophthalmol 1979;63:173-6.

4. Melki TS, et al. A unique epibulbar osseous choristoma. J Pediatr Ophthalmol Strabismus 1990;27:252-4.

5. Ferry AB, Hein HF. Epibulbar osseous choristoma. Am J Ophthalmol 1970;70:764-6.

6. Santora DC, Biglan AW, Johnson BL. Episcleral osteocartilaginous choristoma. Am J Ophthalmol 1995;119:654-5.

7. Boniuk ?, Zimmerman ?. Epibulbar osteoma. Am J Ophthalmol 1962;53:290-6.

\author{
Y. Osoba \\ C.L. Dodd \\ R. Bonshek \\ Royal Manchester Eye Hospital \\ Oxford Road \\ Manchester M13 9WH, UK
}

Sir,

\section{Symptomatic arachnoid cyst presenting as a sixth nerve} palsy

Arachnoid cysts are a rare cause of ocular nerve palsies. These cysts are usually asymptomatic but intracyst haemorrhage or the development of a subdural haematoma may result in symptoms. This case report highlights how the post-traumatic rupture of one such cyst resulted in signs and symptoms of raised intracranial pressure despite the lack of haemorrhage seen on CT scan. This is an infrequent but recognised complication that initially presented to the ophthalmology department. ${ }^{1}$

\section{Case report}

Three weeks after the vigorous to and fro shaking of the head (colloquially known as 'head-banging') at a heavy metal concert a 14-year-old male presented to eye casualty with an occipital headache and a 3 day history of diplopia. On questioning further he stated that the headache had begun after the concert and been associated with neck discomfort. The headache had been steadily increasing in severity since the concert. It was worse on waking in the morning and aggravated by coughing. The headache was also associated with nausea and the patient had vomited once with the pain.

On examination vision was $6 / 6$ in both eyes. He had a right convergent squint that measured 6 dioptres for near and 25 dioptres for distance. Ocular movements confirmed the presence of a right sixth nerve palsy (Fig. 1a). Fundal examination revealed early papilloedema of the right disc (Fig. 1b). The left disc

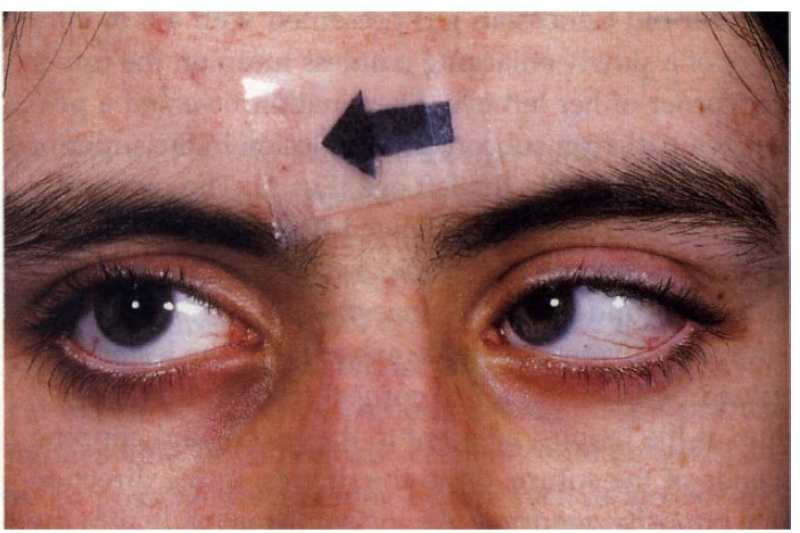

(a)

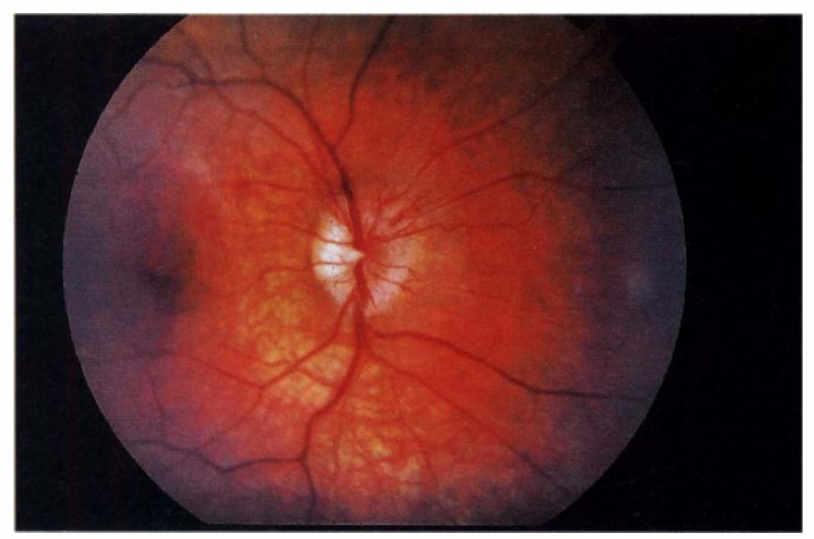

(b)

Fig. 1. (a) Right sixth nerve palsy. (b) Early papilloedema of the right optic disc. 